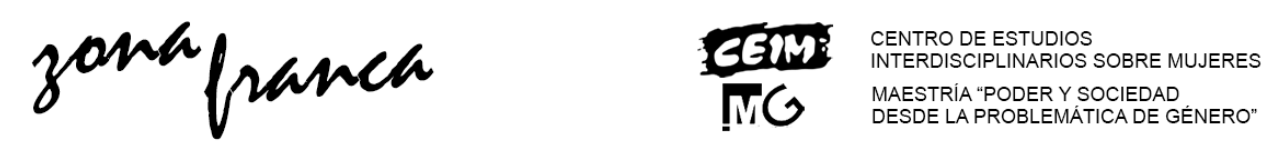

\title{
Discusiones feministas: ¿Qué pasa con el sexo? Reflexiones desde la epistemología feminista
}

Bárbara Yanina Domínguez *

\section{Resumen}

En este artículo pretendo indagar a partir de la llamada epistemología feminista las consideraciones del discurso científico occidental moderno al respecto del "sexo biológico". Desde un análisis que cruza los pensamientos de las norteamericanas Donna Haraway y Anne Fausto-Sterling con la argentina Lucia Ciccia. La intención será, por un lado, poner en diálogo saberes y luchas que nos interpelan en tanto feministas desde diferentes lugares (reales y simbólicos), y, por otro, mostrar la potencialidad radical de la epistemología feminista para lograr este tipo de intercambios y replantear estrategias discursivas y políticas siempre locales y específicas, pero a la vez, solidariamente compartidas en tanto globales.

$\mathrm{Si}$, en "nombre de la ciencia" se ha buscado reiteradamente normalizar y disciplinar los cuerpos bajo etiquetas que responden a probabilidades y contextos políticos, sociales y económicos; quizás, el feminismo nos permita tener esperanzas de que un mundo que nos cobije a todes es posible.

Palabras claves: Epistemología Feminista- Sexo- Biología

Feminist discussions: What about sex? Reflections from the feminist epistemology

\begin{abstract}
* Universidad Nacional de Santiago del Estero - Instituto de Estudios para el Desarrollo SocialConsejo Nacional de Investigaciones Científicas y Técnicas. Contacto: barbi.y.dominguez@gmail.com

Domínguez, Bárbara Yanina. "Discusiones feministas: ¿Qué pasa con el sexo? Reflexiones desde la epistemología feminista" en Zona Franca. Revista del Centro de estudios Interdisciplinario sobre las Mujeres, y de la Maestría poder y sociedad desde la problemática de Género, №27, 2019 pp.103-122. ISSN, 2545-6504 Recibido: 30 de junio 2019; Aceptado: 21 de octubre 2019
\end{abstract}

Revista Zona Franca- Centro de estudios interdisciplinario sobre las mujeres (CEIM)- Maestría poder y sociedad desde la problemática de género (MG), Rosario, Argentina. ISSN, 2545-6504 http://zonafranca.unr.edu.ar/index.php/ZonaFranca| Numero 27 (2019). 
In this article I tried to investigate, from the feminist epistemology, the considerations of modern Western scientific discourse about the "biological sex". From an analysis that exchange the thoughts of the Americans Donna Haraway and Anne Fausto-Sterling with Lucia Ciccia. The intention will be, on the one hand, to put into dialogue knowledge and struggles that challenge us as feminists from different places (real and symbolic), and, on the other hand, to show the radical potentiality of feminist epistemology to achieve this type of exchanges and rethink discursive and political strategies always local and specific, but at the same time, shared in common as global.

If, in "name of science" has been repeatedly sought to normalize and discipline bodies under labels that respond to political, social and economic probabilities and contexts; perhaps, feminism allows us to hope that a world that shelters us all is possible.

Key words: Feminist epistemology- Sex-Biology

\section{Introducción: Mirando el mundo con anteojos violetas}

En este trabajo pretendo indagar a partir de la llamada epistemología feminista' las consideraciones del discurso científico occidental respecto del "sexo biológico". La epistemología, durante mucho tiempo, dividió la producción científica en "contexto de descubrimiento" y "contexto de justificación", encargándose específicamente de analizar este último (Carnap, 1950; Popper, 1996; Bunge, 2000). Pero, a partir de la publicación de "La Estructura de las Revoluciones Científicas" (1962) de Thomas Kuhn estas concepciones fueron sometidas a revisión. La epistemología feminista parte de considerar a la epistemología como una teoría del conocimiento científico que se refiere tanto al estudio de la producción de conocimiento científico, como a la validación del mismo. Entonces, toma en cuenta por un lado, el contexto de descubrimiento, es decir, las circunstancias históricas, psicológicas y sociológicas que llevan a su obtención, y

\footnotetext{
I La epistemología feminista no proporciona un marco de trabajo unificado, por el contrario, está conformada por una complejidad y variedad de teorías, como también de estrategias para lograr la trasformación del orden científico (Blazquez Graf, 2010). Particularmente para realizar este trabajo me baso en una corriente específica que sin negar la posibilidad del conocimiento científico, ni su utilidad; se plantea nuevas formas de considerar su objetividad y rechaza la universalidad y la neutralidad axiológica del mismo. Al respecto véase Haraway, D. (1995). Ciencia, cyborgs y mujeres. La reinvención de la naturaleza. Madrid: Cátedra.
}

Revista Zona Franca- Centro de estudios interdisciplinario sobre las mujeres (CEIM)- Maestría poder y sociedad desde la problemática de género (MG), Rosario, Argentina. ISSN, 2545-6504 http://zonafranca.unr.edu.ar/index.php/ZonaFrancal Numero 27 (2019). 
por otro, el contexto de justificación: los criterios por los cuales se le justifica o invalida (Blazquez Graf, 2010).

De esta forma, las feministas intentan evidenciar cómo "los intereses sociales y políticos, así como los prejuicios personales", han impactado en la producción de conocimiento científico y, continúan haciéndolo hoy en día (Longino en Blazquez Graf, 2010: 25). Siguiendo a Haraway, si tomamos la metáfora de la vista como medio de obtención del conocimiento científico la objetividad se ha autoproclamado como una mirada "desde ningún lugar", una mirada "no marcada", que "reclama el poder de ver y no ser vista, de representar, y de evitar la representación" (1995: 324). El aporte de las feministas ha desmitificado este "truco divino", incorporando el cuerpo, siempre marcado, a la objetividad científica. Es decir, si vemos, lo hacemos a partir de unos ojos, que son los nuestros y que ocupan un lugar especifico y condicionado de vida. Así, como señala FaustoSterling, el conocimiento científico es siempre "situado".

[T]odo saber académico añade hilos a una trama que interconecta cuerpos racializados, sexos, géneros y preferencias. Los hilos nuevos o diferentemente trenzados modifican nuestras relaciones, nuestra situación en el mundo (2006: 22).

Por lo tanto, la propuesta de conocimiento de las feministas está pensada desde una persona que, aunque situada, no está completamente terminada, sino que se re-constituye al tiempo que conoce. Esto evita cualquier esencialismo, incluso de la mirada de las "mujeres" o de las "subyugadas" y en su lugar, promete considerar al conocimiento científico en tanto una "red global de conexiones", de personas incompletas, pero capaces "de unirse a otras, de ver junto a otres $\sin$ pretender ser les otres" (Haraway, 1995: 332)".

\section{Una ciencia socialista y feminista}

" Traducción propia. He preferido utilizar lenguaje inclusivo dado que en inglés no existen las marcas de género que se formarían en el castellano de traducirla al masculino.

Revista Zona Franca- Centro de estudios interdisciplinario sobre las mujeres (CEIM)- Maestría poder y sociedad desde la problemática de género (MG), Rosario, Argentina. ISSN, 2545-6504 http://zonafranca.unr.edu.ar/index.php/ZonaFranca| Numero 27 (2019). 
La primera hipótesis de este trabajo propone situarnos en una sociedad capitalista, patriarcal y racista en la cual el conocimiento científico ha legitimado sistemáticamente la clasificación sexual binaria: hombre/mujer. En este sentido, comparto la posición de Brown que señala

\begin{abstract}
aunque la opresión de la mujer es funcional para el capitalismo, la dominación sexual no va pareja con la dominación de clase ni es una contradicción secundaria, como ha solido pensarse dentro del marxismo [...] la liberación de la clase subalterna no supone necesariamente, ni el mismo movimiento, ni la liberación de las mujeres (2004: 114).
\end{abstract}

Entonces, la categoría patriarcado pretende dar cuenta del control que ejercen los hombres sobre la reproducción humana. Esto implica por un lado, "la regulación de la sexualidad a través del conjunto de permisiones-prohibiciones que organizan el sistema de parentesco en cada sociedad" y por otro, la regulación del "proceso global de la reproducción social" (Ciriza, 1993: 153).

Además, el feminismo de color, desarrollado en EEUU desde los años ochenta, ha dado cuenta de las "opresiones comunes en torno al racismo que experimentan mujeres de procedencias nacionales y étnico-raciales distintas, reconociendo al mismo tiempo la especificidad de sus situaciones concretas" (Eskalera Karakola, 2004: 11). Este señalamiento crítico en conjunto con la colonialidad específica que vive América Latina, hace necesario que tomemos la epistemología feminista para evaluar el panorama actual desde un ámbito transdisciplinar considerando que las opresiones son diversas y múltiples, razón por la cual la interseccionalidad se convierte en una categoría clave "para dar cuenta de lo complejo de los posicionamientos en situaciones de discriminación múltiple" (Campagnoli, 2018).

En este marco, para lograr la reivindicación de los derechos femeninos o de cualquier otra alteridad sexual no hegemónica, no basta con "la incorporación actual de las mujeres a la ciencia", ya que "no es una condición ni necesaria ni suficiente para garantizar la depuración de sesgos sexistas y androcéntricos en su

Revista Zona Franca- Centro de estudios interdisciplinario sobre las mujeres (CEIM)- Maestría poder y sociedad desde la problemática de género (MG), Rosario, Argentina. ISSN, 2545-6504 http://zonafranca.unr.edu.ar/index.php/ZonaFranca| Numero 27 (2019). 
metodología y análisis en general, y en aquellas investigaciones orientadas a la búsqueda de diferencias sexuales en particular" (Ciccia, 2017: 11). Pero entonces, ¿qué nos queda por hacer? Para Haraway "debido a que la ciencia forma parte del proceso de realización y de elaboración de nuestra propia naturaleza, de la constitución de la categoría naturaleza en primer término" tenemos la responsabilidad de re-apropiarnos del conocimiento científico, para lograr una "ciencia socialista y feminista" (1995: 74).

Para ponernos en esa tarea buscaré mostrar la forma en que la biología moderna durante el siglo XIX ha constituido las diferencias sexuales con la finalidad deslegitimar las necesidades sexistas, androcéntricas, racistas y colonialistas de los grupos sociales dominantes generando descripciones parciales de la sexualidad humana, que en lugar de remitir a la existencia de clasificaciones "naturales", terminan dando cuenta de los propios prejuicios de quienes investigan.

\section{El género como construcción social frente al "sexo biológico"}

La construcción del concepto de "género" surgió de la clínica médica durante los primeros tercios del siglo XX. El sexo fue relacionado con el discurso biológico (hormonas, genes, sistema nervioso, morfología) y el género con la cultura (psicología, sociología) (Haraway, 1995). De esta forma, el discurso médico remitía al dualismo naturaleza/cultura, ubicando el sexo con la naturaleza y el género con la cultura. Las feministas de la segunda ola "situadas dentro del entramado binario epistemológico de naturaleza/cultura y sexo/género, [...] se apropiaron de la distinción sexo/género [...] para defender la primacía de culturagénero sobre biología-sexo" (Haraway, 1995: 230) en los debates que se daban en Europa y en los Estados Unidos.

El esfuerzo de las feministas de la época buscaba desplazar a las mujeres de la naturaleza y ubicarlas en la cultura, con la posibilidad de convertirse en "sujetos" es decir, personas sociales que se construyen a lo largo de la historia

Revista Zona Franca- Centro de estudios interdisciplinario sobre las mujeres (CEIM)- Maestría poder y sociedad desde la problemática de género (MG), Rosario, Argentina. ISSN, 2545-6504 http://zonafranca.unr.edu.ar/index.php/ZonaFrancal Numero 27 (2019). 
(Haraway, 1995). De esta forma, autoras muy reconocidas por su lucha epistémica y política como Millet señalaban que "los términos sexo y género no estaban inextricablemente unidos, dado que este último era independiente de la anatomía y la fisiología". Ni siquiera "la endocrinología y la genética" ofrecen "evidencias definitivas de diferencias mentales-emocionales" (Millet en Ciccia, 2017: 120). Con esta cita pretendo mostrar cómo la conceptualización de género implicó una amenaza para el régimen sexual que marcaba la inferioridad de la mujer y habilitó discursos que propusieron desvincular el sexo biológico del psicológico (Ciccia, 2017).

En estas circunstancias, la crítica feminista dirigida al par binario y antagónico naturaleza/cultura fue superficial ya que no logró ahondar en sus bases más fuertes, porque no cuestionó la distinción sexo/género, en razón de que la categoría género "era demasiado valiosa para combatir los omnipresentes determinismos biológicos constantemente desplegados contra las feministas en luchas políticas urgentes sobre las «diferencias de sexo»" (Haraway, 1995: 226).

Con la concepción de género las feministas podían sostener que si las chicas tenían más dificultades con las matemáticas que los chicos, el problema no residía en que eran mujeres, sino en las diferentes oportunidades de unas y otros. Entonces, siguiendo esta linea de argumentación "tener un pene en vez de una vagina es una diferencia de sexo", pero "que los chicos saquen mejores notas en matemáticas que las chicas es una diferencia de género" (Fausto-Sterling, 2006: 18). Así, era posible considerar que la dificultad de las mujeres en las matemáticas era corregible, a pesar de que la diferencia hombre/mujer no lo fuera.

Por lo tanto, se asumió como válida e indiscutible la clasificación binaria de los sexos y las formulaciones de una "identidad esencial como mujer o como hombre permanecieron analíticamente intocadas y siguieron siendo políticamente peligrosas" (Haraway, 1995: 227).

Revista Zona Franca- Centro de estudios interdisciplinario sobre las mujeres (CEIM)- Maestría poder y sociedad desde la problemática de género (MG), Rosario, Argentina. ISSN, 2545-6504 http://zonafranca.unr.edu.ar/index.php/ZonaFranca| Numero 27 (2019). 
Hacia mediados de los ochenta, una desconfianza creciente de la categoría de género fue surgiendo al mismo tiempo que la tercera ola del feminismo irrumpía en el debate para proponer que la categoría "mujer" de las feministas blancas de clase media no incluía a la diversidad de mujeres no hegemónicas que reclaman derechos y un lugar en la historia. Así, autoras como Butler marcaban que el concepto de un yo interior coherente, logrado (cultural) o innato (biológico), es una ficción reguladora innecesaria -más aun, inhibitoria- para los proyectos feministas que producen y afirman el funcionamiento complejo y la responsabilidad (Butler en Haraway, 1995: 228).

Si bien estas discusiones escapan a las pretensiones del presente trabajo, lo que quiero mostrar es cómo "al ceder el territorio del sexo físico, las feministas dejaron un flanco abierto al ataque de sus posiciones sobre la base de las diferencias biológicas". Así, aunque el feminismo ha ganado muchísimas batallas "ha encontrado una resistencia masiva desde los dominios de la biología, la medicina y ámbitos significativos de las ciencias sociales" (Fausto-Stearling, 2006: 18).

De esta forma, las preguntas qué surgen son las siguientes: ¿qué pasa con el "sexo biológico"? Si aceptamos que el "género" es una construcción social, ¿el sexo puede ser considerado de esta forma también? ¿Cómo y quiénes definen a nuestros cuerpos?

\section{Debilidad Natural. Anatomía, genitales y dicotomías}

El discurso sobre las diferencias sexuales comenzó en la antigüedad con la teoría aristotélica-galénica: todo cuerpo tenía un sólo sexo y él de la mujer era más débil "por su falta intrínseca de calor, reflejada en su incapacidad natura"II para exteriorizar el pene" (Ciccia, 2017, p. 35). Sin embargo, con el avenimiento de la ciencia moderna las teorías de la antigüedad fueron re-formadas y se

III Las cursivas son mías.

Revista Zona Franca- Centro de estudios interdisciplinario sobre las mujeres (CEIM)- Maestría poder y sociedad desde la problemática de género (MG), Rosario, Argentina. ISSN, 2545-6504 http://zonafranca.unr.edu.ar/index.php/ZonaFrancal Numero 27 (2019). Página 109 
produjo una re-interpretación de los cuerpos, que se convirtieron en anatómicamente opuestos con dos sistemas reproductores diferentes e independientes, dando origen a una clasificación sexual binaria: hombre/mujer (Ciccia, 2017). Para explicar cómo se originan estas categorías voy a señalar algunos de los hechos más importantes que la precedieron.

Por un parte, en el siglo XVII el llamado "padre" de la filosofía moderna, Descartes, planteó una separación entre la mente y el cuerpo, dando lugar a uno de los grandes dualismos de la modernidad, y señalando en contraposición con Aristóteles que la razón humana era "lo mejor repartido en el mundo" (Descartes, 2004: 68).

Entonces, tanto hombres como mujeres tendrían, en principio, las mismas capacidades mentales (Ciccia, 2007). En este sentido, la dicotomía mente/cuerpo implicaba una jerarquía, el cuerpo era inferior a la mente (Descartes, 2004), a partir de lo cual el hecho de que el hombre pudiera tener una primacía física respecto a la mujer ya no serviría como argumento para justificar la "debilidad natural" de esta.

Por otra parte, desde su gestación en el siglo XVII la ciencia moderna occidental no es concebida como una simple actividad contemplativa sino que tiene una clara pretensión de dominio sobre la naturaleza (Merchant, 1980). En esta época surge la visión mecanicista que supone que podemos comprender el funcionamiento de los entes del mundo sin apelar a fuerzas espirituales u ocultas, considerando leyes naturales del movimiento de la materia, relaciones mecánicas entre partes, e inclusive, apelando a una explicación matemática. (Laguna, 2016: $69)$.

Es decir, la realidad puede ser explicada exclusivamente a partir de leyes físicas producidas entre las entidades que conforman el mundo material. Esta idea defendida por diferentes filósofos de la modernidad (Bacon, Descartes, Locke, 
Hobbes, Galileo, Boyle, etc) ponía en jaque a la libertad, ya que todo parecía estar predeterminado por las leyes que describían el universo.

Una de las consecuencias más importantes de la modificación en la concepción de conocimiento fue la secularización de la naturaleza. Es decir, la naturaleza dejó de tener un carácter sagrado para pasar a ser una exterioridad respecto de lo humano, "un medio para satisfacer necesidades individuales y sociales" (Ulloa, 2001: 192). Entonces, pudo ser explotada y poseída, considerada como simple recurso pasivo, pero, al mismo tiempo, pudo ser intervenida y convertida en un objeto de estudio. Ciccia marca uno de los efectos que esta interpretación tuvo en la forma de realizar los trabajos científicos:

el reinterpretar los seres vivos como cuerpos-máquinas, supuso poder comprender el funcionamiento de Ixs seres humanxs a partir de estudios realizados en animales. Es decir, al estar regidos por los mismos principios según el criterio causa efecto, el sistema fisiológico animal podía extrapolarse a nuestra propia fisiología (2016: 40).

Ahora bien, ante los presupuestos planteados por Descartes y la nueva noción de ciencia las antiguas justificaciones metafísicas acerca de la inferioridad de la mujer respecto al hombre tenían que ser actualizadas con demostraciones experimentales y referirse a una superioridad mental (Ciccia, 2007).

El primer problema qué se le planteó a la ciencia moderna, fue la localización de la "mente".

El médico inglés Thomas Willis [...] fue uno de los primeros en romper con la barrera 'divina' al postular que existían estructuras cerebrales discretas para funciones cognitivas específicas. De esta manera, la mente 'abstracta' inició un proceso de 'materialización cerebral' (Ciccia, 2007: 40).

Es decir, que la "mente" parecía estar ubicada en el cerebro, sin embargo, esto supuso un nuevo problema, ya que el cerebro sólo podía conocerse de

Revista Zona Franca- Centro de estudios interdisciplinario sobre las mujeres (CEIM)- Maestría poder y sociedad desde la problemática de género (MG), Rosario, Argentina. ISSN, 2545-6504 http://zonafranca.unr.edu.ar/index.php/ZonaFrancal Numero 27 (2019). 
manera indirecta. Pasaría mucho tiempo antes de que fuera posible a partir de los avances técnicos y la tecnológicos "convertirlo en un verdadero objeto de estudio, esto es, cuantificable, medible y observable" (Ciccia, 2007: 44). Mientras tanto, fue la anatomía genital la que proveyó pruebas que legitimaran el régimen binario de los sexos. Con respecto a la anatomía moderna conviene hacer algunas aclaraciones.

El cuerpo no siempre fue considerado de la misma manera, en Europa durante la Edad Media la existencia estaba ligada a la red de intercambios, donde el cuerpo no era una frontera. En estas sociedades no era posible concebirse como persona, por fuera o separada de la comunidad (Le Breton, 1990). Durante el Carnaval (fiesta popular medieval) en el Siglo XV las personas se reunían en las calles y copaban la plaza pública, en una confusa mixtura colectiva, la risa borraba jerarquías y mientras durara el festejo triunfaba una liberación transitoria, que abolía provisionalmente las relaciones jerárquicas, los privilegios, las reglas y los tabúes $^{\mathrm{IV}}$. El cuerpo del carnaval para Bajtin es un "cuerpo grotesco" que está en movimiento, no está nunca listo ni acabado: está siempre en estado de construcción, de creación y él mismo construye otro cuerpo; además, este cuerpo absorbe el mundo y es absorbido por éste el rol esencial es atribuido en el cuerpo (2003: 260).

Sin embargo, poco a poco el cuerpo empieza a significar una representación personal, una preocupación por la singularidad propia. El cuerpo durante la modernidad se convierte en la frontera precisa que marca la diferencia entre una persona y otra (Negishi, 2018). En palabras de Bajtin, el cuerpo del canon clásico está "perfectamente acabado, rigurosamente delimitado, cerrado, [...] sin mezcla, individual y expresivo" (2003: 262). La modificación del concepto de cuerpo implicó varías consecuencias:

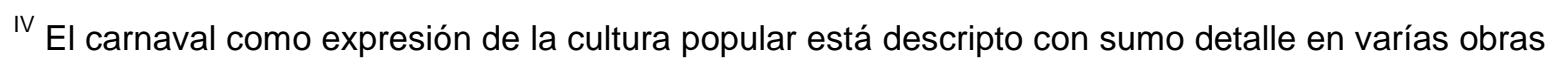
de Bajtin como un momento de disolución de diferencias, sin embargo, las mujeres permanecían en lugares subalternos.

Revista Zona Franca- Centro de estudios interdisciplinario sobre las mujeres (CEIM)- Maestría poder y sociedad desde la problemática de género (MG), Rosario, Argentina. ISSN, 2545-6504 http://zonafranca.unr.edu.ar/index.php/ZonaFranca| Numero 27 (2019). 
En primer lugar, la perfección que se le exige al cuerpo constituye una forma de entender la belleza y la vida, cuestiones que se manifiestan en nuestra actualidad cotidiana, y afecta con más intensidad a los cuerpos femeninos/feminizados.

En segundo lugar, este cuerpo solitario en el mundo, con una aparente capacidad de abstraerse del resto de cuerpos, parece evocar la epistemología moderna de la dominación y al "sujeto moderno" con su capacidad individual de dominar el mundo (la naturaleza).

En tercer lugar, en correlato con el incipiente modelo económico el cuerpo dejó de estar ligado con el ser, para relacionarse con la "posesión": la idea de "mi cuerpo": nació de la emergencia y el desarrollo del individualismo en las sociedades occidentales en el Renacimiento, convierte al cuerpo en el envase del sujeto, el lugar de sus límites y de su libertad (Negishi, 2018: 2).

Así, surgió la paradoja humana de "tener un cuerpo", como si él mismo pudiera ser separado de alguna forma de lo que somos. Este nuevo dualismo comprende al cuerpo aisladamente, en una especie de indiferencia con respecto a la persona que lo constituye (Negishi, 2018).

Finalmente, el cuerpo disociado de la persona se convierte en un objeto de estudio como realidad autónoma. A partir de la lectura de Negishi (2018) la anatomía moderna surgió del trabajo de Leonardo da Vinci (1452-1519) y Vesalio (1514-1564). Mientras los estudios de Leonardo no tuvieron demasiada influencia en su época por permanecer prácticamente en secreto, Vesalio en 1953 publica "De humani corporis fabrica" un tratado de 700 páginas. La mirada de Vesalio sobre la anatomía humana parte de "una mirada alejada que olvida, metodológicamente, al hombre, para considerar tan sólo su cuerpo" (Negishi, 2018: 4). Esto posibilitó la sistematización de las disecciones, que en la Edad Media eran escasas, y, al mismo tiempo, que los cuerpos fueran los instrumentos que servían para verificar las diversas teorías (Ciccia, 2007).

Revista Zona Franca- Centro de estudios interdisciplinario sobre las mujeres (CEIM)- Maestría poder y sociedad desde la problemática de género (MG), Rosario, Argentina. ISSN, 2545-6504 http://zonafranca.unr.edu.ar/index.php/ZonaFranca| Numero 27 (2019). 
Estos estudios de la anatomía consideraron las diferencias genitales para realizar una clasificación binaria y jerárquica, que respaldaba el destino social, dirá Ciccia:

De esta manera, confluyendo el destino social, determinado por las demandas del sistema económico emergente, con el destino biológico, producido por un discurso científico que operó respaldando el destino social, se construyó una lectura dicotómica de los cuerpos donde 'el de la mujer' estaba hecho para garantizar la procreación. Debiendo dicha lectura ser corroborada empíricamente, a partir de 1730 comenzó a visibilizarse el esqueleto de la mujer en la anatomía europea y, entre los años 1750 y 1790 se detalló una compleja red diferencial en relación con 'los dos sexos' (2007: 46).

Así, conforme señala la autora las necesidades del sistema económico emergente influyeron directamente en la ciencia para conformar las teorías de la división sexual. Entonces, una sociedad en vías de industrialización requería una división sexual del trabajo que le fuera funcional a sus fines: "La revolución científica (...) respondió a la vez que proporcionó un apoyo crucial a la polarización de género que el capitalismo industrial exigía. Simpatizando con la creciente división entre masculino y femenino, público y privado, trabajo y hogar" (Fox Keller en Ciccia 2007, 45).

Esta lectura que propone pensar la ciencia como producto de una actividad humana, indistinguible de la cultura que la constituye, confluye con las interpretaciones de la epistemología feminista descriptas al inicio.

La solidez argumentativa que presentaba la anatomía permitía derivar de las diferencias genitales consecuencias psíquicas y políticas. Por ello, siglos después, prevaleció en autores de distintas épocas y contextos (Rousseau, Freud) la opinión de que el "lugar" propio (natural) de la mujer se basaba en sus "características mentales": "si del cuerpo femenino derivan como un exudado natural maternidad, espíritu pragmático y capacidad para asumir la domesticidad,

Revista Zona Franca- Centro de estudios interdisciplinario sobre las mujeres (CEIM)- Maestría poder y sociedad desde la problemática de género (MG), Rosario, Argentina. ISSN, 2545-6504 http://zonafranca.unr.edu.ar/index.php/ZonaFrancal Numero 27 (2019). 
el ingreso de las mujeres al mundo público constituye la peor de las amenazas" (Ciriza, 2002: 224)

La consecuencia necesaria era la exclusión femenina del espacio público y del saber, pero ello debía reforzarse con una educación específicamente destinada a las mujeres que les enseñara a controlar los "impulsos naturales" que amenazaban con destruir el orden social, Rousseau proponía:

\begin{abstract}
Justificad siempre las tareas que impongáis a las niñas, pero imponédselas continuamente. Los dos defectos más peligrosos para ellas, y de que menos sanan cuando una vez los han contraído, son la ociosidad y la indocilidad. Las doncellas deben ser vigilantes y laboriosas; no basta con ello; deben estar sujetas desde muy niñas. Toda la vida han de ser esclavas de la más continua y severa sujeción, que es la del bien parecer. Es preciso acostumbrarlas cuanto antes a la sujeción para que nunca les sea violenta; a resistir todos sus antojos, para someterlas a las voluntades ajenas. Si quisieran estar siempre trabajando convendría precisarlas algunas veces a que holgaran (Rousseau en Ciriza, 2002: 227).
\end{abstract}

De esta forma, aunque aun se carecía de pruebas cerebrales que pudieran justificar la existencia de una desigualdad intelectual, "las características biológicas visibles operaban como explicaciones 'indirectas' de tal justificación; la mujer no estaba hecha para pensar, sino para procrear" Ciccia, 2007: 47).

Finalmente, quisiera destacar que la autora Fausto-Sterling (2006) realizó un profundo estudio sobre el dimorfismo genital y concluyó que en realidad no existen sólo dos sexos, sino que esto está dado por el hecho de "que los médicos piensan que un bebé intersexual es "en realidad» un niño o una niña" y por lo tanto, una vez identificado el sexo "verdadero» podrán con "sus tratamientos quirúrgicos y hormonales [...] llevar a término la intención de la naturaleza (2006: 71).

\title{
Dimorfismo cerebral. El patriarcado cambia de forma
}

Revista Zona Franca- Centro de estudios interdisciplinario sobre las mujeres (CEIM)- Maestría poder y sociedad desde la problemática de género (MG), Rosario, Argentina. ISSN, 2545-6504 http://zonafranca.unr.edu.ar/index.php/ZonaFrancal Numero 27 (2019). 
Como he señalado hasta ahora a partir de la ciencia moderna, los seres vivos fueron analizados, fundamentalmente, por su estructura visible exterior. Entonces, la anatomía como disciplina marcó un presunto dimorfismo genital que fue trasladado al cerebro (en tanto sede de la capacidad de pensar), y las consecuencias psíquicas y políticas de tales dimorfismos ubicó a las mujeres en la esfera privada y a los hombres en la pública. Sin embargo, aquellos argumentos que ligaban la diferencia entre los órganos de reproducción y la estructura cerebral "eran más metafísicos que científicos" (Ciccia, 2007: 58).

Conforme la hipótesis que maneja Ciccia (2007), con la que acuerdo, las nuevas disciplinas científicas o la actualización del conocimiento de las que ya existentes mantienen los sesgos sexistas y androcéntricos clásicos, como también racistas, agregaría yo. De esta forma, la ciencia del cerebro adaptó al nuevo contexto histórico aquellos argumentos que legitiman la existencia del régimen sexual jerárquico y binario.

En un principio, las diferencias entre los cerebros del hombre y la mujeres basaron en el tamaño de los cráneos, considerando que el de mayor tamaño debería ser el de mayor inteligencia:

Durante el siglo XIX eminentes biólogos se dedicaron a comparar los volúmenes craneales. El método consistía en llenar los cráneos de plomo para estimar dicho volumen. Desentendiéndose del tamaño relativo, en términos absolutos los cerebros de las mujeres resultaban menores, deduciéndose entonces que eran menos inteligentes (Fausto-Starling, en Ciccia 2007: 58).

En este sentido, el tamaño relativo era ignorado para legitimar la inteligencia del hombre, frente a la mujer, lo cual muestra importantes sesgos respecto a la manera de llevar a cabo el estudio y en las conclusiones a las que se arribaba.

En paralelo a este tipo de trabajos muy "rústicos" la corriente de "los naturalistas" comenzó a "interesarse por la organización de los seres vivos"

Revista Zona Franca- Centro de estudios interdisciplinario sobre las mujeres (CEIM)- Maestría poder y sociedad desde la problemática de género (MG), Rosario, Argentina. ISSN, 2545-6504 http://zonafranca.unr.edu.ar/index.php/ZonaFrancal Numero 27 (2019). 
(Ciccia, 2007). La disección comenzada por Vesalio ya no se consideraba suficiente, había que situar ese órgano en el organismo vivo y comprender su función específica. Estos estudios llevaron a la idea de "organismo" y posteriormente al concepto de "especie". La embriología, la teoría darwiniana de la evolución y la teoría localizacionista habilitaron la articulación de un discurso que señalaba al hombre como la perfección de la especie mientras que convertía a la mujer en un vestigio primitivo, necesario para preservarla y conservarla. Dice Ciccia "desde una perspectiva funcional/organizacional la mujer fue convertida en una subespecie del hombre" (2007: 61).

La mujer era conceptualizada como un hombre incompleto en términos espaciales y temporales, ya que, el desarrollo embrionario llegaba a un tronco común a partir del cual, el hombre iniciaba un proceso de diferenciación y especialización que implicaba "masculinizar" y "desfeminizar" las distintas partes de su organismo. En consecuencia, el hombre era una mujer pero con estadio mayor de desarrollo.

Es interesante ver cómo estas nuevas teorías se asemejaban muchísimo a las teorías de la antigüedad refutadas. Para no extenderme demasiado, siguiendo a Ciccia (2007) marcaré algunas de las características sexo-específicas que le fueron otorgadas a la mujer conforme sus "capacidades funcionales" a partir de estas reinterpretaciones:

1. La mujer tenía el deber de garantizar la preservación y conservación de la especie. Hasta el punto que fue considerada principalmente como un "cuerpo gestante" con la tarea de cuidar del bienestar y el desarrollo del embrión.

2. La inferioridad mental de la mujer fue considerada una consecuencia correlativa con su función específica, que era el ejercicio de la maternidad. En términos energéticos maternar implicaba un actividad que demandaba cierta energía desplazada de la capacidad intelectual, "ambas actividades serían

Revista Zona Franca- Centro de estudios interdisciplinario sobre las mujeres (CEIM)- Maestría poder y sociedad desde la problemática de género (MG), Rosario, Argentina. ISSN, 2545-6504 http://zonafranca.unr.edu.ar/index.php/ZonaFranca| Numero 27 (2019). 
caracterizadas como inversamente proporcionales en términos energéticos" (Ciccia, 2007: 61).

3. Para asegurar que cada sexo cumplierá sus funciones específicas se argumentó que la maternidad no sólo era clave para la estabilidad social, sino también para el propio bienestar individual de la mujer. En este sentido, ser madre se hacía necesario para la realización y felicidad de la mujer.

4. El positivismo consideró la "virilidad" como sinónimo de "crecimiento mental". La razón era un signo distintivo de superioridad y una característica propia de los hombres, siendo la ciencia hecha por y para ellos. En sentido la teoría darwiniana de la evolución sirvió para consolidar aquellas hipótesis. A su vez, en oposición a la razón como valor dicotómico se representó a la emoción que a su vez, estaba íntimamente ligada a la maternidad.

En definitiva, estas características que fui señalado muestran cómo a pesar de la complejización de las teorías seguían manteniendo el "vínculo causal entre el sexo y una práctica social o un conjunto de características específicas", que según Ciccia, incluso "se repetirá en los discursos científicos que «dialogaron» con la segunda y tercera ola del feminismo" (2007: 82).

Finalmente, algunos estudios revelaban que "la variación individual entre cerebros era tan grande como la encontrada entre los sexos" de forma que la "comparación de cerebros "intra-sexo" no mostraba una coherencia que permitiera agruparlos en una categoría homogénea" (Fausto-Sterling en Ciccia 2007: 82).

Las teorías científicas continuaron actualizándose y en hoy en día, los estudios de las diferencias cerebrales se reúnen en las neurociencias. Según los interesantes análisis de Ciccia estos discursos científicos "legitiman el régimen sexual jerárquico y binario, a la vez que cisexista y heteronormativo" (2007: 158).

\section{Conclusiones: nuevos caminos}

Revista Zona Franca- Centro de estudios interdisciplinario sobre las mujeres (CEIM)- Maestría poder y sociedad desde la problemática de género (MG), Rosario, Argentina. ISSN, 2545-6504 http://zonafranca.unr.edu.ar/index.php/ZonaFrancal Numero 27 (2019). 
Las conclusiones, para mí, son siempre promesas de nuevos recorridos, sirven para dejar planteadas nuevas dudas, porque en definitiva los trabajos científicos, las tesis, las problemáticas de investigación no se terminan, mas que parcialmente. Con esta idea, en este apartado intentaré volver sobre lo expuesto y pensar un poco más allá.

A lo largo del trabajo busqué mostrar desde la epistemología feminista cómo se construye la idea de la "inferioridad natural" de la "mujer" frente al "hombre" a partir de la ciencia moderna occidental, priorizando el debate sobre el "sexo", primero construido desde la anatomía y actualizado desde la ciencia del cerebro.

La modernidad resignificó viejos dualismos, dualismos que priorizan un término del par binario sobre el otro, que vuelven indiscutibles las jerarquías que producen, en tantos son "naturales". Uno de esos dualismos es el de hombre/mujer que reforzado por la idea de la heterosexualidad obligatoria nos acorrala en etiquetas y nos propone funciones específicas conforme a las determinaciones que se hagan de nosotres al momento de nuestro nacimiento (incluso antes).

Por un lado, Fausto-Sterling (2006) se ocupó de estudiar cómo el dimorfismo genital era en realidad una parte de la historia. Con sus estudios demostró que la proporción de personas intersexuales es mayor que la proporción del albinismo, una condición que aunque poco frecuente la mayoría de nosotres habrá visto alguna vez.

Por otro lado, Ciccia (2007) a partir de un meticuloso análisis explicó cómo el dimorfismo genital pasó al cerebro, y de qué manera nuestras capacidades humanas están regidas por nacimiento según tengamos cerebro de "mujer" o de "hombre". La autora a partir de una consistencia argumentativa, de la que espero haber dado cuenta, (en parte al menos) desmitifica esta nueva ciencia que sólo nos trae viejos resabios patriarcales trasformados con nuevos ropajes.

Revista Zona Franca- Centro de estudios interdisciplinario sobre las mujeres (CEIM)- Maestría poder y sociedad desde la problemática de género (MG), Rosario, Argentina. ISSN, 2545-6504 http://zonafranca.unr.edu.ar/index.php/ZonaFranca| Numero 27 (2019). 
Así planteado el problema nos queda pensar ¿qué hacemos ahora? La epistemología feminista ha sabido iluminar con un análisis profundo las más diversas teorías científicas y encontrar en ellas los sesgos masculinistas, racistas, patriarcales y capitalistas que abundan en el sistema en el que vivimos. Las producciones analizadas aquí, dan cuenta de que muchas veces la epistemología feminista se enfrenta en y contra el saber científico, teje redes entre teoría y práctica, entre académicas y militantes, entre epistemología y política, desdibuja fronteras. A partir de la intención de modificar esquemas de pensamiento prefijados, la epistemología feminista no se limita a la "denuncia", sino que tienen una fuerte capacidad propositiva, busca "crear" nuevos mundos posibles.

Lo interesante del movimiento feminista es la posibilidad de articular demandas para llevarlas a la arena pública y dar los debates políticos necesarios para conquistar derechos y buscar garantizarlos. Esa característica del feminismo "de poner el cuerpo", de jugarse por lo que nos parece justo, muchas veces nos cuesta censuras o disciplinamientos. La "normalidad" que describí en el trabajo, el adpatarse a la norma, es el mayor reto que enfrentamos, porque no queremos adecuarnos a las normas hechas por hombres blancos heterosexuales para hombres blancos heterosexuales. Allí, las lineas son finas, y corremos el riesgo de quedar fuera del sistema mismo, lo que a mi modo de ver, tampoco es útil.

¿Podemos entonces abandonar toda etiqueta? O quizás, al menos ¿dejar de pensar que esas etiquetas traen consecuencias de tipo estructurales? ¿Será que tendremos la capacidad de considerar que hay hombres sin pene, mujeres con pene y personas que no se identifican con ninguna de las "opciones disponibles"? Muchas veces sucede que hemos asimilado/interiorizado las discriminaciones, y tal como señala Simone de Beauvoir en El segundo sexo "el opresor no sería tan fuerte si no tuviese cómplices entre los propios oprimidos”. ¿Podemos desterrar esos esquemas mentales y construir otros, que no nos marquen quién ser de acuerdo a discursos ajenos? ¿Será la epistemología feminista la herramienta adecuada para "interrumpir esos mensajes de dominio" como quisiera Haraway?

Revista Zona Franca- Centro de estudios interdisciplinario sobre las mujeres (CEIM)- Maestría poder y sociedad desde la problemática de género (MG), Rosario, Argentina. ISSN, 2545-6504 http://zonafranca.unr.edu.ar/index.php/ZonaFranca| Numero 27 (2019). 
No tenemos una tarea fácil, pero no estamos solas, el feminismo siempre abraza muy fuerte cuando pensamos que nos quedamos sin alternativas.

Finalmente, para todas estas preguntas aún no tengo respuestas, pero sí estoy segura de que el feminismo es el camino, que teje solidaridad política en todos lados con toda persona que lo necesite, que está para incluir lo que el sistema cataloga de "diferente", de "anormal", y que por suerte, estamos tan convencidas de nuestra propia capacidad de lucha que no pararemos hasta lograrlo.

\section{Bibliografía}

BAJTIN, Mijail, (2003). La cultura popular en la Edad Moderna y el Renacimiento. Madrid: Alianza.

BLAZQUEZ GRAF, Norma (Comp) (2010). Investigación feminista: epistemología, metodología y representaciones sociales. México: Centro de Investigaciones Interdisciplinarias en Ciencias y Humanidades Universidad Nacional Autónoma de México.

BRAH, Avtar; ANZALDÚA Gloria; HOOKS, Bell; SANDOVAL, Chela; BHAVNANI, Khum-khum; MORALES, Aurora; COULSON, Margaret; MOHANTY, Chandra Tapalde; (2004). Otras inapropiables (Feminismos desde las fronteras). Madrid: Traficantes de sueños.

BROWN, Josefina (2004) "Derechos, ciudadanía y mujeres" en Argentina Política y Cultura, núm. 21, primavera, pp. 111-125 Universidad Autónoma Metropolitana Unidad Xochimilco Distrito Federal, México. Disponible en: http://www.redalyc.org/articulo.oa?id=26702108

CAMPAGNOLI, Mabel Alicia (2018). "Epistemologías críticas feministas. Aproximaciones actuales", en Descentrada 2(2), e047. Disponible en https://www.descentrada.fahce.unlp.edu.ar/article/view/DES047/9807 
CICCIA, Lucia. (2017). La ficción de los sexos: Hacia un pensamiento Neuroqueer desde la epistemología feminista. (Tesis Doctoral). UBA, Buenos Aires.

CIRIZA Alejandra (1993) "Feminismo, política y crisis de la modernidad", en El Cielo por Asalto, año 2, núm. 5, otoño, pp. 153-154. Buenos Aires.

CIRIZA, Alejandra (2002) "Pasado y presente. El dilema Wollstonecraft como herencia teórica y política", en Teoría y Filosofía Política: La Recuperación de los Clásicos en el Debate Latinoamericano, compilado por Atilio Borón y Alvaro De Vita. Buenos Aires: CLACSO - USPI.

DESCARTES, René (2004). Discurso del método. Argentina: Ediciones Colihue SRL.

FAUSTO-STERLING, Anne. (2006). Cuerpos sexuados. La política de género y la construcción de la sexualidad. Barcelona: Melusina.

HARAWAY, Donna (1995). Ciencia, cyborgs y mujeres. La reinvención de la naturaleza. Madrid: Cátedra.

LE BRETON, David (1995). Antropología del cuerpo y modernidad. Buenos Aires: Nueva Visión.

NEGISHI, Analia (2018). "Cuerpo y Modernidad”. Buenos Aires: Liliana Lopez Foresi. Disponible en https://lilianalopezforesi.com.ar/en/noticia/cuerpo-ymodernidad.

ULLOA, Astrid (2001). "Transformaciones en las investigaciones antropológicas sobre naturaleza, ecología y medio ambiente" en Revista colombiana de antropología, 37, 188-232. 